\title{
IDENTIDADE PESSOAL: DA ALIENAÇÃO AO ENGAJAMENTO POLÍTICO EM CHARLES TAYLOR E JEAN-JACQUES ROUSSEAU
}

\section{Caius Brandão ${ }^{1}$}

Universidade Federal de Goiás (UFG)

(iD) https://orcid.org/0000-0001-8336-1466

Email: caiusbrandao@gmail.com

\section{RESUMO:}

$\mathrm{O}$ artigo desenvolve um estudo comparativo das noções de identidade pessoal e engajamento político nas filosofias de Charles Taylor e Jean-Jacques Rousseau. A partir de uma pesquisa bibliográfica de fontes primárias e secundárias, conclui-se que ambos os filósofos postulam uma natureza ontologicamente dialógica da identidade pessoal, logo, essencialmente dependente de relação duradoura com os outros. Por outro lado, Taylor e Rousseau equacionam o problema da alienação política na modernidade com base em princípios distintos que servem de fundamento para o engajamento político dos cidadãos.

PALAVRaS-CHAVE: Identidade Pessoal; Individualismo; Engajamento Político; Taylor; Rousseau.

\section{PERSONAL IDENTITY: FROM ALIENATION TO POLITICAL ENGAGEMENT IN CHARLES TAYLOR AND JEAN-JACQUES ROUSSEAU}

\begin{abstract}
:
The paper carries out a comparative analysis of the notions of personal identity and political engagement in the thought of Charles Taylor and Jean-Jacques Rousseau. From a bibliographical study of primary and secondary sources, it is concluded that both philosophers postulate an ontologically dialogical nature of personal identity, thus, essentially dependent on lasting relationship with others. On the other hand, Taylor and Rousseau equate the problem of political alienation in modernity based on distinct principles that serve as the justification for the political engagement of citizens.
\end{abstract}

KEYWORDS: Personal Identity; Individualism; Political Engagement; Taylor; Rousseau. 


\section{Introdução}

Inicialmente, é importante ressaltar a relevância da filosofia de Jean-Jacques Rousseau para o pensamento ético e político do canadense Charles Taylor. De acordo com Ruth Abbey, além de Aristóteles, Hegel, Herder, Heidegger e Wittgenstein, Rousseau é um dos pensadores que mais influenciaram a obra de Taylor (ABBEY, 2000). Em um de seus trabalhos mais influentes, As fontes do selfa construção da identidade moderna, Taylor cita Rousseau nominalmente mais de uma centena de vezes e dedica boa parte da seção de um de seus capítulos ao impacto do legado do genebrino na constituição da identidade moderna ${ }^{2}$. Afora as consonâncias entre Taylor e Rousseau, são também notáveis algumas dissonâncias entre os dois autores, o que ficará parcialmente evidenciado ao longo deste artigo.

Em segundo lugar, deve-se ter em conta que a discussão aqui proposta tem como pano de fundo o debate hodierno entre filósofos liberais e comunitaristas, o qual tomou forma nas últimas quatro décadas. De um lado, têm-se pensadores como John Rawls, Ronald Dworkin, Thomas Nagel e Thomas Michael Scanlon que pertencem à corrente do liberalismo contemporâneo, do outro, estão os filósofos da escola comunitaristas, tais como Charles Taylor, Michael Sandel, Alasdayr MacIntyre e Michael Walzer. No artigo intitulado Liberalismo y comunitarismo: un debate inacabado, Rubén Benedicto Rodríguez afirma que Taylor sente-se incomodado com o rótulo de comunitarista por considerá-lo "confuso e de duvidosa capacidade descritiva" (RODRÍGUEZ, 2010, p. 210) ${ }^{3}$. Mas quais são as principais polêmicas entre os teóricos liberais e comunitaristas? De acordo com Rodríguez,

[...] um dos aspectos que identifica o grupo dos comunitaristas é que, frente aos outros filósofos que têm destacado a preeminência dos direitos individuais ou defendido a neutralidade do Estado sobre as concepções do bem - por exemplo, Rawls, Dworkin, Hayek ou Nozick -, eles ressaltam a necessidade da participação na vida pública. Para isso, consideram necessária uma maior unidade entre os membros da comunidade do que a declarada pelos liberais. (RODRÍGUEZ, 2010, p. 203)4

Além da questão acerca da neutralidade do Estado frente à concepção de vida boa ou à importância da participação na vida pública, outro aspecto que caracteriza o debate entre os teóricos do liberalismo e do comunitarismo é o peso que cada corrente atribui à comunidade na construção da identidade pessoal (RODRÍGUEZ, 2010). Enquanto os liberais alegam rejeitar as concepções metafísicas de pessoa e articular formulações independentes de qualquer concepção de natureza humana, os comunitaristas criticam tais posições, alegando que a noção de natureza humana que subjaz a essas formulações de pessoa é, na verdade, "atomista, procedimental, incorpórea e desvinculada da comunidade" (BORGES, 2012, p. 91). Em suma, para

\footnotetext{
2 Ver "A Natureza como Fonte", na Parte IV - A Voz da Natureza (TAYLOR, 1989). Além dessa obra, Taylor também faz uso da teoria de Rousseau em seus livros Multiculturalismo e $A$ ética da autenticidade.

3 Tradução nossa do original em espanhol: "confuso y de dudosa capacidad descriptiva."

4 Tradução nossa do original em espanhol: "uno de los rasgos que identifica al grupo de los comunitaristas es que, frente a otros filósofos que han destacado la preeminencia de los derechos individuales o que han defendido la neutralidad del Estado sobre las concepciones del bien — por ejemplo, Rawls, Dworkin, Hayek o Nozick-, aquéllos subrayan la necesidad de la participación en la vida pública. Para ello estiman necesaria una mayor unidad entre los miembros de la comunidad que la que declaran los liberales."
} 
os teóricos liberais, a identidade pessoal seria desvinculada da comunidade ${ }^{5}$, enquanto que, para os comunitaristas, ela seria arraigada e dependente dela.

Em Contextos da justiça: filosofia política para além do liberalismo e comunismo, Rainer Forst atribui à filosofia política de Hobbes o surgimento da concepção atomística de organização social como germe do individualismo moderno:

A crítica da "imagem de homem" que está na base da teoria liberal é tão velha quanto a própria teoria política liberal. Desde que Hobbes compreendeu os homens "como se tivessem acabado de brotar da terra e subitamente, como cogumelos, amadurecidos sem nenhum tipo de relação uns com os outros" (Hobbes, 1642, p. 109), desde que ele arrancou o homem do universo aristotélico-escolástico e, com isso, preparou o caminho para o liberalismo, este se vê confrontado com a objeção do atomismo. Essa crítica orienta-se especificamente contra a teoria liberal do contrato legitimador do Estado. Imaginar as instituições sociais e políticas como o resultado de um contrato entre pessoas independentes, livres e iguais significa compreender erroneamente o caráter histórico dessas instituições e das pessoas, como se estas fossem "tão só uma multidão atomística de indivíduos juntos" (Hegel, 1821, § 273) com a finalidade de dar-se uma constituição. [...] Se o homem deve ser imaginado como zoon politikon no interior de uma "pólis" eticamente abrangente ou como citoyen político virtuoso, se como parte do "espírito objetivo", da eticidade de um povo, ou como membro de uma classe social numa situação histórica determinada, tudo isso varia segundo as diferentes direções da crítica ao liberalismo. Porém, é comum a todos esses críticos interpretar o "eu liberal" (liberal self) como um produto abstrato artificial de uma teoria que se empenha na defesa dos direitos individuais e, para esse fim, coloca o indivíduo autônomo como seu cerne normativo. (FORST, 2010, p. 15).

Em face do debate teórico entre os liberais (que buscam proteger as demandas do indivíduo sobre a comunidade) e os comunitaristas (que visam resguardar as demandas da comunidade sobre os indivíduos), existe, na prática, o ideal que toma como fundamento um tipo de individualismo altamente enraizado na cultura moderna. A preponderância do egoísmo sobre a preocupação com os outros, do ostracismo sobre a vida compartilhada, enfim, do interesse particular sobre o interesse público, é uma realidade contemporânea que justifica o estudo sobre a relação entre identidade pessoal e alienação política.

A seguir, serão colocadas em discussão as críticas de Taylor e de Rousseau contra o individualismo egoísta da modernidade e da contemporaneidade, bem como a maneira como eles propõem equacionar o problema da alienação da vida política.

\footnotetext{
5 Neste ponto, torna-se essencial explicitar alguns sentidos atribuídos por Rousseau e Taylor ao termo “comunidade". Sobre essa questão, em Misreading One's Sources: Charles Taylor's Rousseau, Jonathan Marks faz a seguinte ponderação em nota de rodapé: "I am aware that the term, community, is also controversial. It is somewhat arbitrary but, I think, not inconsistent with Rousseau's or Taylor's usage, to understand community as a group united by language, 'manners and morals,' a common way of life and a (perhaps quite limited) common good. Admittedly, Rousseau usually uses 'community' in a stronger sense, to refer to the association that is formed by the social pact ('Each member of the community gives himself to it at the moment of its formation' [SC, III, 365; 54]). But he also uses it nonpolitically to refer to the 'little community' at Clarens (Julie, II, 619; 507). I will most often use community in a political sense, and so will be considering its coercive power. This usage is somewhat narrower than but not inconsistent with Taylor's usage. It is both broader, because it includes political associations that hardly meet the exacting standards of the Social Contract, and narrower than Rousseau's" (MARKS, 2005, p. 120). Da mesma maneira, neste artigo, o termo "comunidade" será utilizado no sentido de comunidade política.
}

BRANDÃO, Caius. Identidade pessoal: da alienação ao engajamento político em Charle Taylor e Jean-Jacques Rousseau. Griot : Revista de Filosofia, Amargosa - BA, v.18, n.2, p.161-175, dezembro, 2018. 


\section{Individualismo e Alienação da Esfera Pública}

Na obra The Ethics of Authenticity (1991), Charles Taylor propõe que o individualismo egoísta, a razão instrumental e a alienação da esfera pública são fenômenos correlatos e concomitantes na modernidade, resultando na perda de significado e desaparecimento de horizontes morais, na supressão de propósitos de vida mais elevados, bem como na redução da liberdade política. Após reconhecer que o individualismo é, para muitos, um dos bens mais valiosos da vida moderna, o qual concede às pessoas o direito de escolha de seus próprios modos de vida ou de eleger os seus próprios ideais morais, o filósofo canadense alerta para o desenvolvimento contemporâneo de um lado obscuro do individualismo. Quando os indivíduos se transformam em sujeitos autocentrados, suas vidas tornam-se mais rasas e estreitas, pobres em significado, resultando em menos preocupação com outros ou com a sociedade. Tais desenvolvimentos seriam algumas das consequências nefastas de sociedades mais permissivas, dando lugar à "me generation", onde o que prevalece é um tipo de individualismo narcísico e hedonista. É o que Taylor chama de individualismo da autorrealização, o qual teria se difundido desde a década de 1960, particularmente, nas sociedades ocidentais. Esta cultura da autorrealização seria responsável pela desconsideração do indivíduo por tudo aquilo que vai além das necessidades privadas. Na avaliação de Taylor, a força moral que está por trás desse tipo de identidade pessoal marcada pelo individualismo egoísta é o ideal de autenticidade. Mais à frente, esse ideal será tratado com maior profundidade. Por ora, será suficiente demonstrar a consonância entre as preocupações de Taylor e de Rousseau com individualismo da autorrealização que se enraizou na cultura moderna ou, em termos mais rousseauistas, na cultura das sociedades burguesas de seu tempo.

Em diversas de suas obras ${ }^{6}$, particularmente, no Discurso sobre a origem e os fundamentos da desigualdade entre os homens (Segundo discurso), Rousseau desferiu ataques viscerais contra os homens da sociedade civil. No artigo intitulado Rousseau and the Problem of Bourgeois Society, Arthur M. Melzer articula uma análise criteriosa da crítica de Rousseau contra o individualismo egoísta de seus contemporâneos. Melzer afirma que, na visão do genebrino:

[...] o burguês está escravizado por seu empenho para fazer uso de outros homens, embora ele não o saiba. A interiorização de sua escravidão - que a esconde dele - divide a sua alma. Aqui, então, está a fonte da falta de unidade. $O$ burguês está dividido entre as inclinações de seu egoísmo e a necessidade interiorizada de servir aos outros que o próprio egoísmo produz. Ele vive preocupado com os outros - para controlá-los - embora ele apenas ame a si mesmo. Como diz Rousseau, ele oscila entre ser bom para si e bom para os outros. Tendo interiorizado a autocontradição de fazer uso dos outros homens, ele se encontra dividido por um egoísmo altruísta (MERLZER, 1980, p. 1027). ${ }^{7}$

\footnotetext{
${ }^{6}$ Ver Emílio, ou da educação, Cartas Escritas da Montanha, e Carta a Voltaire.

${ }^{7}$ Tradução nossa do original em inglês: "Thus the bourgeois is enslaved by his effort to use other men, though he does not know it. The internalization of his enslavement - which conceals it from him - splits his soul. Here, then, is the source of disunity. The bourgeois is divided between the inclinations of his selfishness and the internalized need to serve others that very selfishness produces. He spends his life concerned with others - to control them - though he loves only
} 
Mais à frente, Melzer conclui:

\begin{abstract}
Mas a "devoção" do burguês aos outros - sua cortesia, solicitude, conformidade e moralismo - é meramente o produto contraditório, portanto hipócrita e alienante, de seu egoísmo. Ele está dividido, não entre o amor de si e o amor-próprio, mas entre os seus fins egoístas de segurança, honra e poder (que decorrem tanto do amor de si quanto do amor-próprio) e os seus "serviços" desgastantes aos outros, o "eu social" falso exigido por seu uso dos homens como meio (MERLZER, 1980, p. 1028). ${ }^{8}$
\end{abstract}

Nesta sua explanação, mesmo que indiretamente, Melzer certamente faz alusão à celebre passagem do Emílio, ou da educação, onde Rousseau afirma:

Aquele que, na ordem civil, quer conservar o primado dos sentimentos da natureza não sabe o que quer. Sempre em contradição consigo mesmo, sempre passando das inclinações para os deveres, jamais será nem homem, nem cidadão; não será bom nem para sim mesmo, nem para os outros. Será um desses homens de hoje, um francês, um inglês, um burguês; não será nada. (ROUSSEAU, 2004, p.12).

Conforme aponta Neiva Afonso Oliveira em Rousseau e Rawls - o contrato em duas vias, para contrapor o egoísmo burguês, Rousseau propõe a preponderância da vontade geral, ou seja, do bem comum sobre o interesse particular. Assim sendo, ela conclui:

[...] o cidadão de Rousseau não é um homem acomodado, não é um burguês individualista, acostumado às benesses do poder; a estes Rousseau repudia com veemência. Em sua contundente oposição à sociedade de sua época, o autor identificou a íntima relação entre democracia e igualdade e não as colocou apenas como princípios a ser seguidos, mas a visualizou como condição de uma sociedade digna para o cidadão (OLIVEIRA, 2000, p. 110).

Uma vez demonstrada a paridade entre as críticas de Taylor e de Rousseau contra o individualismo egoísta, agora se faz necessário explicitar as fontes do ideal de autenticidade que dão sustentação a esse tipo de individualismo, conforme o entendimento do nosso autor canadense. Primeiramente, Taylor reconhece que a ética da autenticidade surge no final do século XVIII a partir de formas anteriores de individualismo. Neste ponto, Taylor faz menção ao que ele chama de individualismo da racionalidade desengajada, defendida por René Descartes, bem como ao individualismo de John Locke, cuja teoria postula que o eu e suas vontades são anteriores aos deveres sociais. Porém, ao mesmo tempo, Taylor pondera que a autenticidade surge no período do romantismo, o qual é crítico à racionalidade

himself. As Rousseau says, he floats between being good for himself and good for others. Having internalized the selfcontradiction of using other men, he is divided by selfish selflessness."

8 Tradução nossa do original em inglês: "But the bourgeois' 'devotion' to others-his politeness, solicitude, conformity and moralism - is merely the contradictory, hence hypocritical and divisive, product of his selfishness. He is divided, not between self-love and amour-propre, but between his selfish ends of security, honor and power (which stem from both self-love and amour-propre) and the all-consuming 'services' to others, the phony 'social self' required by his use of men as means."

BRANDÃO, Caius. Identidade pessoal: da alienação ao engajamento político em Charle Taylor e Jean-Jacques Rousseau. Griot : Revista de Filosofia, Amargosa - BA, v.18, n.2, p.161-175, dezembro, 2018. 
desengajada e à visão atomística de organização social, as quais desprezam os vínculos com a esfera pública (TAYLOR, 1991).

De acordo com Taylor, para uma compreensão mais aprofundada acerca do desenvolvimento da ética da autenticidade seria necessário compreender a noção, amplamente difundida no século XVIII, de que os seres humanos seriam dotados de um senso moral intuitivo. Em outras palavras, que a moralidade do indivíduo contaria com uma voz interior para nos dizer qual seria a coisa certa a fazer. Ainda de acordo com Taylor, "isso é parte da enorme virada subjetiva da cultura moderna, uma nova forma de interioridade, na qual passamos a nos conceber como seres com profundidades internas" (TAYLOR, 1991, p. 26) ${ }^{9}$. Taylor salienta que, primeiro, essa nova forma de introspecção não excluía a relação dos seres humanos com entes transcendentes, podendo, inclusive, ser considerada uma forma de se alcançar a Deus, tal como fora defendido por Santo Agostinho, e que os primeiros desenvolvimentos dessa nova visão estavam fundamentados em argumentos teístas ou mesmo panteístas. O nosso autor canadense argumenta que Jean-Jacques Rousseau, não teria sido o pioneiro dessas mudanças, mas que a popularidade de sua obra se deve, pelo menos parcialmente, ao fato de ele ter articulado com sucesso aquilo que já estaria em voga na cultura de sua época. Ao se referir à noção de que a salvação moral viria deste íntimo contato consigo próprio, Taylor afirma: "Rousseau chega a nomear o contato íntimo consigo mesmo, mais fundamental do que qualquer visão moral, que é uma fonte de alegria e contentamento: 'o sentimento da existência"" (TAYLOR, 1991, p. 27). ${ }^{10}$ Nesta passagem, o pensador canadense parece cometer um equívoco ao confundir o conceito de "le sentiment de l'existence" com "la conscience", na filosofia de Jean-Jacques Rousseau. ${ }^{11}$ Conforme argumenta Jonathan Marks, se o sentimento de existência fosse o mesmo que a consciência, então teríamos que admitir que esse sentimento não é anterior à sociedade, mas dependente dela, na medida em que a consciência é algo que somente se manifesta no homem em relação com outros ${ }^{12}$ (MARKS, 2005). Contudo, se o sentimento de existência é o que Rousseau afirma ser, ou seja,

[...] um contentamento cuja fonte é "nada externo a nós, nada além de nós mesmos e de nossa própria existência" (Reveries, 89; I, 1047), então ele representa um obstáculo para o argumento que Taylor deseja fazer, que não podemos ser nós mesmos se não participarmos

\footnotetext{
9 Tradução nossa do original em inglês: "This is part of the massive subjective turn of modern culture, a new form of inwardness, in which we come to think of ourselves as beings with inner depths."

10 Tradução nossa do original em inglês/francês: "Rousseau even gives a name to the intimate contact with oneself, more fundamental than any moral view, that is a source of joy and contentment: "le sentiment de l'existence."

${ }^{11}$ Esta observação foi feita por Jonathan Marks. O comentador americano argumenta acertadamente que: "in fact, for Rousseau, the sentiment of existence offers no moral guidance. Solitary, amoral, natural man enjoys 'the sentiment of his present existence' (Second Discourse, SD hereafter, I, 21; III 144). Man's 'first sentiment was that of his existence' (SD, II, 2; III, 164). The passage Taylor cites from the Reveries nowhere mentions morality and even suggests that a man who indulges himself in the sentiment of existence may develop a distaste for his duties; such indulgence is appropriate only for a man who 'can do nothing more in this world to benefit himself or others' (Reveries, 89; I, 1047)" (MARKS, 2005, p. 120 e 121).

12 De fato, conforme Rousseau afirma no Emílio, ou da educação: "é do sistema moral formado por essa dupla relação, consigo mesmo e com seus semelhantes, que nasce o impulso da consciência" (ROUSSEAU, 2004, p. 411).
}

BRANDÃO, Caius. Identidade pessoal: da alienação ao engajamento político em Charle Taylor e Jean-Jacques Rousseau. Griot : Revista de Filosofia, Amargosa - BA, v.18, n.2, p.161-175, dezembro, 2018. 
de uma vida comum e reconhecermos os nossos laços com os outros (MARKS, 2005, p. 123).

Por outro lado, poder-se-ia argumentar que, na perspectiva defendida por Taylor, todo horizonte de sentido é necessariamente articulado linguisticamente. Então, sendo a linguagem um fenômeno compartilhado coletivamente - mesmo quando o horizonte de sentido for uma conexão interna com a natureza, portanto, um contentamento cuja fonte não seria "nada externo a nós", como quer Rousseau tal horizonte é necessariamente constituído por meio de um diálogo com os nossos "significant others".

Para Taylor, outro fator significativo para que o ideal de autenticidade se tornasse decisivo na cultura moderna foi, decididamente, o pensamento de Johann Gottfried von Herder, filósofo e teólogo prussiano, contemporâneo de Rousseau. Herder defendia a ideia de que "cada um de nós tem a sua maneira original de ser humano: cada pessoa possui a sua própria 'medida'. (...) Existe uma determinada maneira de ser humano que é a minha maneira." (TAYLOR, 1994, p. 50). Ainda de acordo com Taylor, a partir daí, surge a noção de que ser verdadeiro consigo mesmo significa seguir a sua própria originalidade - algo que somente o próprio indivíduo pode elaborar a partir de sua interioridade. Assim, o princípio da originalidade teria tomado corpo e se tornado uma das fontes morais do ideal moderno de autenticidade, "incluindo suas formas mais degradadas, absurdas ou trivializadas" (TAYLOR, 1991, p. 29), em outras palavras, quando o ideal de autenticidade se degenera no individualismo da autorrealização e na alienação política dos indivíduos.

\section{Engajamento Político}

Para avançar sobre as questões pertinentes ao engajamento político, antes, será necessário compreender uma configuração incontornável para a formação da identidade pessoal, de acordo com Taylor e Rousseau. Neste sentido, aqui, o ponto de partida representa, ao mesmo tempo, mais um ponto de encontro entre os pensamentos de ambos os autores, qual seja: o papel imprescindível dos outros na formação e manutenção da identidade pessoal.

Em referência ao Segundo discurso de Rousseau, Claudio Reis explica que "é só na medida em que passa a existir para os outros, que passa a "olhar e quere ser olhado", que o indivíduo constrói a consciência de si mesmo" (REIS, 2010, p.10). Em diversas passagens de sua obra Jean-Jacques Rousseau e la teoria della società bene ordinata, Maurizio Viroli confirma o mesmo entendimento ${ }^{13}$ :

\footnotetext{
A identidade pessoal é um produto das opiniões que outros possuem de nós e é, por conseguinte, o resultado da comparação entre indivíduos. Consequentemente, no caso dos homens que vivem isolados em seu estado natural, não se pode falar de identidade pessoal. (...) Destarte, a sociedade
} ${ }^{13}$ Na edição em língua inglesa, Jean-Jacques Rousseau and the 'Well-Ordered Society' (1988), ver pp. 68, 70-72, 85-
87, 102-104, e 111-113. 
- a rede de relações duradouras entre homens - é a condição necessária para a criação da identidade individual (VIROLI, 1988, p. 4). ${ }^{14}$

Aqui, é importante destacar a distinção que Viroli faz entre identidade individual e identidade coletiva. A primeira é formada a partir das relações de um indivíduo com outros homens no segundo estágio do estado de natureza, também conhecido como "a idade de ouro". A segunda é aquela adquirida pelo homem da sociedade civil, ou seja, a de cidadão de um corpo político (VIROLI, 1998, pp. 191 e 220).

Taylor, por sua vez, também defende o papel indispensável dos outros para a formação da identidade pessoal: "Um ser humano sozinho é uma impossibilidade, não apenas de fato, mas também de direito. Na ausência do diálogo contínuo com uma comunidade $[\ldots]$ a agência humana $[. .$.$] não seria apenas impossível, mas$ inconcebível" (TAYLOR, 1985, p. 8). ${ }^{15}$ Para Taylor, a contribuição de "outros significativos" (significant others) para a formação da identidade de um indivíduo se dá não somente no início, mas ao longo de toda a sua vida. Nas palavras do filósofo: "Mas, independente de como alguém se sente sobre isso, a construção e sustentação da nossa identidade, na ausência de um esforço heróico para abandonar a existência comum, permanecem dialógicas ao longo de nossas vidas" (TAYLOR, 1991, p. 35). ${ }^{16}$ A natureza dialógica do self evocada por Taylor nesta passagem é o que ele nomeia de "característica geral da vida humana". ${ }^{17}$

Contudo, o filósofo canadense vai ainda mais longe ao defender que a sociedade é necessária não somente para a construção da identidade pessoal, como também para a proteção da liberdade individual. Em outras palavras, para que a liberdade do indivíduo possa se realizar serão necessárias certas condições sociais. Então, Taylor recomenda que os cidadãos deliberem conjuntamente sobre as leis, as instituições políticas e a cultura de sua sociedade (TAYLOR, 1985). Em seu artigo $A$ crítica comunitarista de Charles Taylor à concepção de liberdade (negativa), Cesar Augusto Ramos argumenta que o filósofo defende "o autogoverno participativo como valor crítico central da tradição republicana cívico-humanista para a realização e constituição de uma sociedade livre, democrática e igualitária" (RAMOS, 2014, p. 33).

14 Tradução nossa da edição em inglês: "Personal identity is a product of the opinions that others have of us and is thus a result of the comparison between individuals. Consequently, in the case of men living alone in their natural state, one cannot speak of personal identity (...) Thus society, the network of enduring relations between men, is the necessary condition for the creation of individual identity."

15 Tradução nossa do original em inglês: "A human being alone is an impossibility, not just de facto, but as it were de jure. Outside of the continuing conversation of a community . . human agency . . . would be not just impossible but inconceivable".

16 Tradução nossa do original em inglês: "But however one feels about it, the making and sustaining of our identity, in the absence of a heroic effort to break out of ordinary existence, remains dialogical throughout our lives".

17 Em oposição à concepção do "self pontual" em Locke, conforme observado por Paulo Roberto M. de Araujo, em Charles Taylor: para uma ética do reconhecimento (2004), Taylor defende que o self pode existir somente num espaço de indagações morais, o que determina a relação incontornável entre a identidade pessoal e a noção de bem moral. Ruth Abbey, por sua vez, no Capítulo 2, Interpreting Selfhood, de seu livro intitulado Charles Taylor (2000), aponta que, além da natureza dialógica do self, Taylor apresenta as seguintes dimensões ontológicas da identidade pessoal: a) autointerpretação - uma das características que distingue os seres humanos dos demais animais seria a sua natureza autointerpretativa. Nas palavras de Taylor: "man is a self-defining animal" (TAYLOR, 1985, p. 55); b) propósito - os selves seriam seres com propósitos originais e intrínsecos. Portanto, possuir propósitos seria uma das características ontológicas da identidade pessoal; e, finalmente, c) linguagem - o que significa, acima de tudo, que os seres humanos seriam "language users".

BRANDÃO, Caius. Identidade pessoal: da alienação ao engajamento político em Charle Taylor e Jean-Jacques Rousseau. Griot : Revista de Filosofia, Amargosa - BA, v.18, n.2, p.161-175, dezembro, 2018. 
Até aqui, o republicanismo de Taylor parece beber da fonte rousseauísta. Entretanto, é justamente o pensamento político de Rousseau que é alvo críticas contundentes do pensador canadense. Em The Ethics of Authenticity, Taylor afirma:

A liberdade autodeterminada tem sido uma ideia de imenso poder em
nossa vida política. Na obra de Rousseau, ela assume uma forma política
na noção de um estado do contrato social fundado em uma vontade geral,
a qual, precisamente por ser a forma de nossa liberdade comum, não pode
surgir nenhuma oposição em nome da liberdade. Essa ideia tem sido uma
das fontes intelectuais do totalitarismo moderno, começando, pode-se
argumentar, com os jacobinos. (TAYLOR, 1991, p. 48). ${ }^{18}$

Quando Taylor diz "um estado do contrato social fundado em uma vontade geral" ele deve conceber uma vontade geral anterior ao pacto social para que ela possa servir de causa e fundamento do Estado. Mas na verdade, como quer Rousseau, a vontade geral é a vontade de um corpo político que passa a existir imediatamente após o pacto social. No Contrato social, o filósofo de Genebra afirma de forma categórica:

Imediatamente, em vez da pessoa particular de cada contratante, esse ato de associação produz um corpo moral e coletivo composto de tanto membros quantos são os votos da assembleia, o qual recebe, por esse mesmo ato, sua unidade, seu eu comum, sua vida e sua vontade (ROUSSEAU, 1999, p. 22).

Se a vontade geral é posterior ao contrato social, então ela não pode cumprir o papel que Taylor lhe atribui. O que dá causa e fundamento ao Estado não é a vontade geral, mas o pacto que cada indivíduo faz com o todo. Logo, para Rousseau, o contrato social é causa e fundamento do corpo coletivo - a vontade geral assegura a sua manutenção. Mais à frente será oportuno retornar a essa questão sobre como Rousseau fundamenta o Estado.

Isto posto, faz-se necessário retificar o entendimento de Taylor de que contra a vontade geral não possa "surgir nenhuma oposição (...)" porque seria ela o fundamento do Estado. Para que se possa manter fiel ao pensamento de Rousseau, seria, pois, imprescindível reconhecer que a conformidade à vontade geral é sim inescapável ao alcance da virtude em uma sociedade bem ordenada. Nas palavras do genebrino:

Quereis que a vontade geral seja cumprida? Fazei com que todas as vontades particulares convirjam para ela; e como a virtude não é senão esta conformidade da vontade particular à geral, para dizer, numa palavra, a mesma coisa, fazei reinar a virtude (ROUSSEAU, 2006a, p. 96).

Já em sua obra Argumentos filosóficos (2000), Taylor formula o entendimento de que a liberdade - compreendida como ausência de domínio -, a falta de

\footnotetext{
18 Tradução nossa do original em inglês: "Self-determining freedom has been an idea of immense power in our political life. In Rousseau's work it takes political form, in the notion of a social contract state founded on a general will, which precisely because it is the form of our common freedom can brook no opposition in the name of freedom. This idea has been one of the intellectual sources of modern totalitarianism, starting, one might argue, with the Jacobins."
}

BRANDÃO, Caius. Identidade pessoal: da alienação ao engajamento político em Charle Taylor e Jean-Jacques Rousseau. Griot : Revista de Filosofia, Amargosa - BA, v.18, n.2, p.161-175, dezembro, 2018. 
diferenciação e a estrita coesão de propósitos entre os cidadãos teriam sido defendidas pelo filósofo de Genebra em seus escritos políticos e influenciado regimes totalitários hodiernos. ${ }^{19} \mathrm{Em}$ suas próprias palavras:

Em Rousseau, três coisas parecem inseparáveis: a liberdade (o nãodomínio), a ausência de papéis diferenciados e um propósito comum dotado de firme coesão. Todos temos de ser dependentes da vontade geral a fim de evitar que surjam formas bilaterais de dependência. Essa tem sido a fórmula para as mais terríveis formas de tirania homogeneizante, tendo início com os jacobinos e estendendo-se aos regimes totalitários de nosso século (TAYLOR, 2000, p. 259).

Em Misreading One's Sources: Charles Taylor's Rousseau (2005), Jonathan Marks tece um rosário de críticas à filosofia de Taylor e faz reparos às interpretações taylorianas do pensamento de Rousseau que ele considera equivocadas. De acordo com Marks,

Embora as preferências políticas de Taylor sejam mais ou menos liberais, ele oferece um ataque teórico contra o individualismo e um fundamento para a tirania social mais poderoso do que qualquer outro que possa ser encontrado no pensamento de Rousseau. Seria insensato negar que o resultado político preferido de Rousseau é, na prática, mais distante do liberalismo do que o de Taylor, mas seria igualmente insensato deixar de observar que a filosofia política de Rousseau fornece pontos de resistência às exigências de uma comunidade que a filosofia política de Taylor não disponibiliza (MARKS, 2005, p. 120). ${ }^{20}$

Aqui, todavia, será colocado em evidência somente um dos pontos mais relevantes do artigo de Marks para a discussão acerca de como os dois filósofos, Taylor e Rousseau, equacionam o problema do engajamento político de membros de uma determinada comunidade. Em relação a esta questão, apesar da formulação inicial articulada por Marks ser considerada por ele próprio como simplista demais, ela resume com bastante clareza as posições iniciais de Taylor e Rousseau:

Podemos formular provisoriamente pelo menos uma diferença significativa entre Rousseau e Taylor da seguinte maneira: enquanto que o último justifica a comunidade em termos de identidade, Rousseau a justifica em termos de identidade moral ou cidadania; e, enquanto a defesa de Taylor é,

19 Em uma palestra proferida durante o VIII Colóquio Nacional Jean-Jacques Rousseau (realizado em Curitiba, PR, em maio de 2017), com o título Igualdade e reconhecimento em Rousseau: a leitura contemporânea de Charles Taylor, Renato Moscateli ressalta alguns aspectos das obras políticas de Rousseau que teriam sidos desprezados por Taylor, tais como: a) diferentes níveis de integração social e de igualdade em repúblicas elogiadas por Rousseau demonstram não ser necessária uma homogeneidade social estrita entre os cidadãos para a realização do bem comum; b) no Contrato social, Rousseau prega expressamente a proibição à intolerância religiosa, o que expressa uma política do reconhecimento à diversidade religiosa entre os membros de uma sociedade bem ordenada; e c) posições distintas entre os homens e as mulheres que deveriam ser assumidas numa sociedade republicana, de acordo com a concepção de Rousseau acerca de supostas características naturais que seriam próprias de cada sexo.

${ }^{20}$ Tradução nossa do original em inglês: “Although Taylor's political preferences are more or less liberal, he offers a theoretical attack on individualism and a foundation for social tyranny more powerful than any to be found in Rousseau's thought. It would be foolish to deny that Rousseau's preferred political outcome is, practically speaking, further from liberalism than Taylor's, but it would be equally foolish not to notice that Rousseau's political philosophy provides points of resistance to a community's demands that Taylor's political philosophy does not." 
portanto, potencialmente bastante ampla em relação à gama de comunidades que ela poderia justificar, a de Rousseau parece bastante restrita (MARKS, 2005, p. 130). ${ }^{21}$

Na leitura que Marks faz da obra de Taylor o que justifica o engajamento político é a dependência do indivíduo de ter a sua identidade criada e mantida por uma comunidade. Marks argumenta ainda que, para Rousseau, o indivíduo só ficaria realmente obrigado àquela comunidade que fosse a responsável pela formação de sua moralidade ou cidadania. Ele observa que enquanto a posição de Rousseau é mais exclusiva, no sentido de que a identidade formada pela comunidade é mais qualificada (a de ser moral ou cidadão), a de Taylor é demasiadamente inclusiva, permitindo que o indivíduo se sinta obrigado a qualquer comunidade, até mesmo aquelas que são ilegítimas ou degeneradas, já que mesmo elas oferecem horizontes de significados onde a linguagem e a racionalidade estão disponíveis a qualquer um de seus membros.

Entretanto, o comentador americano parece não ter dado a devida importância ao fato de que Taylor, conforme salientado anteriormente, justifica a participação política dos indivíduos também na necessidade de realização de suas liberdades individuais, conforme pode ser apreendido na seguinte formulação de Taylor:

Se a realização da nossa liberdade depende em parte da sociedade e da cultura onde vivemos, então nós usufruímos de uma liberdade mais completa se contribuímos para determinar a forma dessa sociedade e dessa cultura. E nós só podemos fazê-lo pelos instrumentos de decisão comum. (TAYLOR, 1985, p. 208).

Nessa passagem, o argumento de que a realização das liberdades individuais justifica a participação política dos indivíduos parece estar calcado em um tipo de razão instrumental que foi alvo de duras críticas do próprio filósofo canadense, particularmente, em The Ethics of Authenticity.

Assim como Taylor, Rousseau reconhece a natureza dialógica da identidade pessoal, mas ele irá encontrar outros fundamentos para a obrigação do indivíduo com a sua comunidade, além de propor um princípio distinto do de Taylor para a manutenção dessa obrigação. Natália Maruyama no Capítulo 3 - Os Sentimentos Morais e a Obrigação, de sua obra $A$ contradição entre o homem $e$ o cidadão: consciência e política segundo J.-J.Rousseau, argumenta que, para o genebrino, "os princípios que levam o indivíduo a agir em função do bem público ou comum não estão vinculados aos cálculos da razão (MARUYAMA, 2001, p. 111). Isso quer dizer que o interesse particular, por si mesmo, não seria capaz de produzir o engajamento político dos indivíduos com o bem público. O que fundamenta a obrigação dos indivíduos com os deveres sociais "é a convenção, ainda que tácita, estabelecida entre os membros do corpo político no momento do contrato" (MARUYAMA, 2001,

\footnotetext{
${ }^{21}$ Tradução nossa do original em inglês: "We may provisionally formulate at least one serious difference between Rousseau and Taylor as follows: whereas the latter justifies community in terms of identity, Rousseau justifies it in terms of moral identity or citizenship; and whereas Taylor's defense is therefore potentially quite broad with respect to the range of communities it could justify, Rousseau's seems quite narrow."
} 
p. 92). Maruyama lembra que em Cartas escritas da montanha, Rousseau faz a seguinte ponderação:

O que é que faz com que o Estado seja um Estado? É a união de seus membros. E de onde nasce a união de seus membros? Da obrigação que os liga. Tudo está de acordo até aqui. Mas qual é o fundamento dessa obrigação? [...] a convenção de seus membros (ROUSSEAU, 2006b, pp. 318 e 319$)$.

Ainda de acordo com Maruyama, se por um lado, a convenção é o que oferece o fundamento para o engajamento político, a consciência moral garante a sua manutenção. Em suas palavras:

\begin{abstract}
A originalidade da teoria da consciência de Rousseau é concebê-la, não apenas como um substrato da ordem universal, ou como um "instinto divino", mas como base da obrigação, na medida em que, ao estender os interesses do indivíduo à utilidade e ao bem público, embora não seja causa da associação política, é o que a conserva. [...] É a consciência que, segundo Rousseau, confere ao indivíduo a capacidade de obrigar-se a si mesmo, de impor-se as leis e as obrigações morais e políticas (MARUYAMA, 2001, p. 113).
\end{abstract}

A despeito das dissonâncias entre os pensamentos políticos de Taylor e Rousseau evidenciadas acima, os dois filósofos voltam a convergir ao defenderem o respeito à liberdade, igualdade e dignidade dos indivíduos como condição sine qua non para o bem viver dos cidadãos. Na perspectiva compartilhada entre os dois pensadores, $o$ ideal da democracia participativa aparece como o mais adequado para o engajamento político dos cidadãos.

\title{
Conclusão
}

A influência de Jean-Jacques Rousseau na filosofia de Charles Taylor não dissimula algumas divergências significativas entre as suas teorias. Isto fica claro quando são colocados em evidência os conceitos de identidade pessoal e de engajamento político no pensamento dos dois pensadores - questão que fomenta diferenças entre liberais e comunitaristas. Não obstante, tanto Taylor como Rousseau combatem o individualismo egoísta da modernidade, e defendem um tipo de individualismo que pode ser chamado de holista e expressivista. Eles afirmam a natureza dialógica do self enquanto característica ontológica do homem, mas sem deixar de considerar como importantes algumas conquistas da era moderna, como a possibilidade de uma identidade pessoal autêntica, original e autônoma. Ambos reconhecem também que, sem relações duradouras com "outros significativos", a identidade pessoal seria simplesmente inviável e até mesmo inconcebível. Outras conquistas individuais, tais como a liberdade, a igualdade e a dignidade também carecem de uma comunidade humana para se concretizarem, aquiescem os filósofos. Entretanto, de acordo com Taylor, é exatamente essa mesma dependência indivíduo que justifica o engajamento político de cada cidadão. Aqui, Rousseau segue em outra direção, e toma a convenção, mesmo que tácita, como fundamento da obediência do indivíduo aos deveres sociais, ou seja, o respeito à palavra dada. A questão que 
permanece aberta é se seria a dependência, com quer Taylor, ou o livre compromisso do indivíduo, como defende Rousseau, que melhor poderia estabelecer vínculos benfazejos e duradouros com a sua comunidade. 


\section{Referências}

ABBEY, Ruth. Charles Taylor. Teddington: Acumen Publishing Limited, 2000. ARAUJO, Paulo. Charles Taylor: para uma ética do reconhecimento. São Paulo: Edições Loyola, 2004.

BORGES, Charles. A constituição do self moderno: Rainer Forst entre liberais e comunitaristas. Intuitio Vol. 5, $\mathrm{N}^{\mathrm{o}}$ 1, pp. 90-105, 2012.

FORST, Rainer. Contextos da justiça - Filosofia política para além de liberalismo e comunitarismo. Tradução de Denilson Luís Werle. São Paulo: Boitempo Editorial, 2010.

MARKS, Jonathan. Misreading One's Sources: Charles Taylor's Rousseau. American Journal of Political Science, Vol. 49, Nº 1, pp. 119-134, 2005.

MELZER, Arthur. Rousseau and the Problem of Bourgeois Society. The American Political Science Review, Vol. 74, No 4, pp. 1018-1033, 1980.

MOSCATELI, Renato. Igualdade e reconhecimento em Rousseau: a leitura contemporânea de Charles Taylor. Palestra no VIII Colóquio Nacional Jean-Jacques Rousseau. Curitiba, 2017.

MURUYAMA, Natalia. A contradição entre o homem e o cidadão: consciência e política segundo J.-J.Rousseau. São Paulo: Humanitas: Fapesp, 2001.

OLIVEIRA, Neiva. Rousseau e Rawls - Contrato em duas vias. Porto Alegre: EDIPUCRS, 2000.

RAMOS, Cesar. A crítica comunitarista de Charles Taylor à concepção de liberdade (negativa). Filosofia Unisinos, Vol. 15, N. 1, pp. 20-34, 2014.

REIS, C. Sobre um "individualismo" de Jean-Jacques Rousseau. Philósophos -

Revista de Filosofia, V. 5, N. 2, p. 4-34, set. 2010.

RODRÍGUEZ, Rubén. Liberalismo y comunitarismo: un debate inacabado.

Studium: Revista de Humanidades, V. 16, pp. 201-229, 2010.

ROUSSEAU, J.-J. Discurso sobre a origem e os fundamentos da desigualdade entre os homens. Trad. de Lourdes Santos Machado. São Paulo: Nova Cultural, 1988.

(Coleção Os Pensadores)

O contrato social ou princípios do direito político. Trad. de Antonio de Pádua

Danesi. São Paulo: Martins Fontes, 1999.

Escritos sobre a religião e a moral - Carta a Voltaire. In: Clássicos da Filosofia:

Cadernos de Tradução n. 2. Trad. de Adalberto L. Vicente e Ana Luiza S. Camarani.

Organização e apresentação de José Oscar de Almeida Marques. São Paulo:

IFCH/UNICAMP, 2002.

Considerações sobre o governo da Polônia e sua reforma projetada. In: Rousseau

e as Relações Internacionais. Trad. Sérgio Bath. São Paulo: Editora UNB,

FUNANG/IPRI, Imprensa Oficial do Estado de São Paulo, 2003.

Emílio ou da educação. Trad. de Roberto Leal Ferreira. São Paulo: Martins

Fontes, 2004.

Economia (moral e política). In: Verbetes políticos da enciclopédia / D.

Diderot e J. D'Alembert. São Paulo: Discurso Editorial; UNESP, 2006a.

Cartas Escritas da Montanha. Trad. Maria Constança Peres Pisarra e Maria

das Graças Sousa. São Paulo: EDUC; UNESP, 2006b.

BRANDÃO, Caius. Identidade pessoal: da alienação ao engajamento político em Charle Taylor e Jean-Jacques 
TAYLOR, Charles. Philosophy and the Human Science: Philosophical Papers, Volume 2. Cambridge: Cambridge University Press, 1985.

As fontes do self-a construção da identidade moderna. São Paulo: Edições

Loyola, 1989.

The Ethics of Authenticity. Cambridge: Harvard University Press, 1991.

Multiculturalismo - examinando a política do reconhecimento. Lisboa:

Instituto Piaget, 1994.

Argumentos filosóficos. São Paulo: Edições Loyola, 2000.

VIROLI, Maurizio. Jean-Jacques Rousseau and the "well-ordered society". Cambridge: Cambridge University Press, 1988.

Autor(a) para correspondência: Caius Brandão, Universidade Federal de Goiás, Faculdade de Filosofia, Av Esperança, SN, Campus Samambaia - Conj. Itatiaia, CEP 74690-900, Goiânia - GO, Brasil.caiusbrandao@gmail.com 